\title{
Background on international activities on protein quality assessment of foods
}

\author{
G. Sarwar Gilani* \\ Nutrition Research Division, Health Canada, 251 Sir Frederick Banting Driveway, Ottawa, Ontario, \\ Canada K1A OKO \\ (Submitted 3 August 2011 - Accepted 12 December 2011)
}

\begin{abstract}
The subject of protein quality assessment of foods and diets was addressed at the Codex Committee on Vegetable Proteins (19821989), FAO/WHO (1989, 2001) and WHO/FAO (2002) expert reviews. These international developments are summarized in this manuscript. In 1989, a Joint FAO/WHO Expert Consultation on Protein Quality Evaluation reviewed knowledge of protein quality assessment of foods, and specifically evaluated amino acid score corrected for protein digestibility, the method recommended by the Codex Committee on Vegetable Proteins. The report of the Consultation published in 1991 concluded that the Protein Digestibility-corrected Amino Acid Score (PDCAAS) method was the most suitable approach for routine evaluation of protein quality for humans. The Consultation recognized that the amino acid scoring pattern proposed by FAO/WHO/UNU (1985) for preschool children was at that time the most suitable pattern for calculating PDCAAS for all ages except infants in which case the amino acid composition of human milk was recommended to be the basis of the scoring pattern. The rat balance method was considered as the most suitable practical method for predicting protein digestibility by humans. Since its adoption by FAO/WHO (1991), the PDCAAS method has been criticised for a number of reasons. The FAO/WHO (2001) Working Group on analytical issues related to protein quality assessed the validity of criticisms of the PDCAAS method. While recognizing a distinct regulatory use of protein quality data, the Working Group recommended that the PDCAAS method may be inappropriate for the routine prediction of protein quality of novel and sole source foods which contain high levels of anti nutritional factors; and that for regulatory purposes, the method should be revised to permit values of $>100$ for high quality proteins. In evaluating the recommendations of the Working Group, the WHO/FAO (2002) Expert Consultation on Protein and Amino Acid Requirements endorsed the PDCAAS method with minor modifications to the calculation method but also raised several issues. These included the calculation of scoring patterns; prediction of amino acid digestibility by faecal and ileal methods; reduced bioavailability of lysine in processed proteins; truncation of the amino acid score and consequent PDCAAS value; protein digestibility as a first limiting factor in determining the overall available dietary nitrogen; and the calculation of amino acid score for a dietary protein mixture. These concerns were considered particularly important in relation to the regulatory aspects of protein quality of foods, and their resolution was urgently recommended through a new separate expert review.
\end{abstract}

Key words: FAO: WHO: Protein digestibility: Amino acid score: Protein efficiency ratio

The only true measurement of protein quality for human use is growth and/or metabolic balance evaluation carried out in suitable subjects of the target population. Recognising that such studies cannot be carried out on a routine basis for reasons of both cost and ethics, it is essential to develop in vitro or animal assays that correlate well with data from human experiments undertaken for each food product. To ensure accuracy and wide applicability, the routine methods must measure all the basic parameters that determine the quality of a protein, including quantities of dietary indispensable amino acids (IAA), digestibility of protein, and bioavailability of amino acids $^{(1)}$.

\begin{abstract}
Major reviews and evaluations of protein quality assessment methods including those based on rat growth and nitrogen balance as well as amino acid scoring techniques were carried out at the Airlee Conference in 1981 sponsored by Howard University, USDA and US National Science Foundation ${ }^{(2)}$; Codex Committee on Vegetable Proteins $(1982-1989)^{(3)}$, FAO/WHO $(1989,2001)^{(4,5)}$ and WHO/FAO/UNU $(2002)^{(6)}$. The criteria and significance of dietary protein sources in humans were also discussed at an international symposium held in San Francisco in $1999^{(7)}$. The purpose of this manuscript is to summarize these international developments on the protein quality evaluation of foods and diets.
\end{abstract}


Routine protein quality assessment methods based on rat growth and nitrogen balance

The protein efficiency ratio (PER) was the first method adopted for routine evaluation of the protein quality of foods. The PER is a standardized method ${ }^{(8)}$ that involves feeding of a test protein diet and a casein control diet (both containing $10 \%$ protein, $\mathrm{N} \times 6.25)$ to weanling rats for a period of four weeks, and the PER values are calculated by dividing the weight gain by the amount of protein consumed. To compare PER values of diets determined in different laboratories, the PER values are adjusted to an assumed value of 2.5 for a casein control.

For several decades, it has been generally recognized that the PER method, although it is simple, does not meet any other criteria of a valid bioassay such as precision, reproducibility, proportionality to protein quality and low $\operatorname{cost}^{(9)}$. The failure of the PER assay to properly credit protein used for maintenance purposes is the main criticism of the method. The poorer the quality of dietary protein, the larger is the error that is introduced because of this failure to make allowance for maintenance. For this reason, PER values are not proportional to protein quality. The lack of proportionality makes the PER method unsuitable for use in protein rating systems that are based on both the "quality" (PER) and "quantity" of protein. Use of such a rating system (protein rating = grams protein in a Reasonable Daily Intake X PER) which is the official method of regulating protein claims of foods sold in Canada ${ }^{(10)}$, assumes that PER values are proportional, (i.e. a PER of $2 \cdot 0$ is twice as good as a PER of 1.0 ). This assumption is not correct.

A multi-dose slope ratio growth assay utilising a reference protein for assessing protein quality of foods was introduced $^{(11)}$. There were two versions of the slope ratio assay, the relative nutritive value (RNV) and the relative protein value (RPV). The RNV method includes the measurement of the slope of the linear portion of the line relating growth response to nitrogen intakes of rats fed zero and three or more levels of dietary protein, expressed on a scale relative to a value of 1 or 100 for a standard protein. The RPV method is the same as the RNV method except that data for the non-protein group are omitted when the slope of the response is calculated. The RPV modification of the slope ratio assay appeared to overcome the problem (excessive downward curvature) found with the RNV procedure when proteins severely limiting in lysine were assayed. However, the RPV method was reported to yield erroneously high values for some proteins due to parallelism, i.e., lines having similar slope but different intercepts on the weight gain axis $^{(11)}$. Parallelism is frequently encountered with mixtures of proteins limiting in threonine or co-limiting in lysine and threonine. The RNV method is superior to the RPV method in terms of agreement with amino acid scores, and is probably the best assay for predicting protein quality by rat growth ${ }^{(12)}$.

Net protein ratio (NPR) which is a two-dose assay (i.e., the test protein and a zero protein level) gives the same result as a valid slope ratio method ${ }^{(9)}$. The NPR method overcomes the major weakness in the PER assay by adding the weight loss of rats fed a non-protein diet to the weight gain of rats fed the test protein ${ }^{(13)}$. However, the assumption must be made that the protein required to prevent weight loss of rats fed the non-protein diet is equivalent to the protein needed for maintenance. As normally carried out NPR values are uncorrected. However, the scale for relative NPR, RNPR (NPR of test protein expressed relative to a value of 100 for NPR of reference protein) is 1 to 100 as it is for biological value $(\mathrm{BV}=$ the proportion of absorbed nitrogen that is retained for maintenance and/or growth) and net protein utilization $(\mathrm{NPU}=$ the proportion of nitrogen intake that is retained, i.e., the product of $\mathrm{BV}$ and protein digestibility) ${ }^{(9)}$.

The RNPR method, which is a modified NPU method (based on body weight), provides similar results to the RNV method $^{(12)}$. The RNPR method is more economical and does not require complex statistical analysis of the data as is necessary for the multi-dose assays such as RPV and RNV. The RNPR method (two weeks) is shorter than the standard PER method (four weeks) and therefore is less expensive, and RNPR values (unlike PER values) are proportional to each other in protein quality within reasonable limits. Several collaborative studies ${ }^{(14-16)}$ have demonstrated that RNPR is more accurate and reproducible than PER and the adoption by AOAC of the NPR method (expressed as RNPR) as official first action as an alternative to the PER method was recommended $^{(16)}$.

In the standard PER and NPR methods, foods are tested at $10 \%$ dietary protein, and unsupplemented casein is used as the reference protein. However, diets containing $8-10 \%$ protein from unsupplemented casein do not meet rat growth requirements for sulphur amino acids ${ }^{(17)}$. Therefore, methionine supplemented casein was used as the reference protein in the determination of RNPR. The RNPR method includes the use of an $8 \%$ protein level because high quality proteins such as egg and casein (normally used as reference proteins) show peak PER or NPR values at about $8 \%$ compared to dietary protein levels of 10,12 or $16 \%{ }^{(15)}$. Similarly, the BV and NPU values for egg and casein were higher at $8 \%$ than at 12,16 , or $20 \%$ dietary protein $^{(18)}$.

The nitrogen utilization (NU) method $^{(19)}$ is a modification of NPR, the factor of maintenance being calculated instead of measured $(\mathrm{NU}=$ body weight gain of test group $+0 \cdot 1$ (initial + final body weight)/nitrogen consumed by test group). In a collaborative study ${ }^{(20)}$, RNU (NU of test protein/ $\mathrm{NU}$ of reference protein $\times 100$ ) gave essentially the same values as RNPR for lactalbumin, RNPR of 87 vs. RNU of 87 ; for egg white, RNPR of 97 vs. RNU of 97; for wheat gluten, RNPR of 32 vs. RNU of 31; and for wheat gluten + SPI, RNPR of 64 vs. RNU of 64. Similarly, a comparison of RNPR and RNU values for 16 protein products showed a strong correlation between RNPR and RNU $(r=0.98)^{(19)}$. The RNU method eliminates the feeding of a "zero" protein diet to a group of rats; thus, less labour is required for the RNU procedure compared to the RNPR procedure.

It is well known that the requirements of rats for sulphur amino acids are much higher than those of humans and that any rat growth assay (especially those that do not credit protein used for maintenance such as PER) will underestimate 
the protein quality for humans of any protein product limiting in sulphur amino acids such as soyabean protein products, peanuts, and grain legumes or pulses, i.e., peas, beans, and lentils. Modifications to correct for the higher essential amino acid requirements of rats compared with humans have been suggested for accurate prediction of protein quality for humans using rat bioassays ${ }^{(21)}$. In comparing IAA requirements of rats and humans, the rat requirement for sulphur amino acids was about $50 \%$ higher than that of humans, whereas the differences between the requirements for other IAA were relatively small ${ }^{(22)}$. Based on these comparisons, a factor of 1.5 was selected to correct the RNPR values (casein + methionine $=100$ ) of protein products limiting in sulphur amino acids for rat growth. The resultant data were called corrected RNPR (CRNPR) values ${ }^{(22)}$. The high CRNPR values (up to $97 \%$ ) for the soyabean protein products and their mixtures with beef (100\%) were in close agreement with protein quality data for these products reported in experiments with humans ${ }^{(23)}$. The use of the correction factor would be appropriate in predicting protein quality for adults and children but not for infants because of higher IAA requirements compared to adults and children ${ }^{(24)}$.

Unlike other rat growth methods for evaluating protein quality, the CRNPR method would not discriminate against proteins deficient in sulphur amino acids. However, the CRNPR method has been criticized for using a constant factor of 1.5 regardless of degree of deficiency of the sulphur amino acids ${ }^{(3)}$. It was suggested that the correction factor should be (in part) based on the total sulphur amino acid content of the test protein product. According to this suggestion, the CRNPR method would not be very efficient, because its calculation would also require determination of total sulphur amino acids.

\section{Major scientific reviews of protein quality evaluation methodology Airlee conference (1981)}

A major review and evaluation of protein quality methods were undertaken at the Airlee Conference ${ }^{(2)}$ in 1981, organized by Howard University and USDA (United States Department of Agriculture) and financed by the National Science Foundation, Washington, D.C. It was generally agreed at this conference that the PER method should be replaced by a more precise and appropriate method. Although the RNPR method was considered to be an improvement over the PER method, a method based on comparison of amino acid content of food with human amino acid requirements (amino acid scoring system) was considered to be the most suitable approach for assessing protein quality of foods ${ }^{(1)}$. It was also recommended that amino acid score should be corrected for incomplete digestibility of protein, and for unavailability of individual amino acids, especially those that are susceptible to damage by processing treatments. This conference recognized the need for further research to standardize amino acid analysis methodology, to improve methods for the determination of digestibility of protein and the bioavailability of amino acids, and to further investigate human amino acid requirements for developing an accurate amino acid scoring pattern ${ }^{(2)}$.

\section{Deliberations of the Codex Committee on Vegetable Proteins regarding protein quality assessment (1982-1989)}

The recommendations of the Airlee Conference were taken up by the Codex Committee on Vegetable Proteins (CCVP) ${ }^{(3)}$, which was established to develop international Codex standards (including protein quality requirements) for vegetable protein products. An Ad Hoc Working Group on Protein Quality Measurement was formed to conduct cooperative research to identify the most promising methods for evaluation of protein quality of foods. In collaborative studies organized by USDA ${ }^{(25)}$, seventeen protein products were studied for amino acid profiles, for protein and amino acid digestibility (by in vitro and rat balance methods), amino acid availability (by chemical methods and rat, Escherichia coli, and Streptococcus zymogenes growth methods), and for protein quality indices based on PER, NPR, RNPR, NPU, and BV. Interlaboratory studies on protein digestibility determinations were also organized by the USDA to test the appropriateness of the in vitro methods ${ }^{(26)}$, and to standardize the rat balance method $^{(27)}$. Results of these and other related studies were discussed at the Fifth Session of $\mathrm{CCVP}^{(3)}$ held in 1989 in Ottawa, Canada.

Based on the recommendations of the Ad Hoc Woking Group on Protein Quality Measurement, the CCVP at its Fifth Session agreed that amino acid score, corrected for true digestibility of protein (as determined by the rat balance method) was the most suitable method for the routine assessment of protein quality of vegetable protein products and other food products ${ }^{(3)}$. Amino acid score was based on the amount of the first limiting amino acid, and its calculation included the use of the requirement pattern suggested by the $\mathrm{FAO} / \mathrm{WHO} / \mathrm{UNU}^{(24)}$ for the preschool child. Because the protein quality methodology had broad implications beyond the purview of the CCVP, the CCVP recognized the need for the wider scientific community to address issues such as amino acid methodology, protein digestibility, amino acid bioavailability, and correlations in humans. The CCVP accordingly recommended at its Fifth Session in 1989 that an FAO/WHO expert consultation should be held to review the protein quality methodology. Such a consultation was requested to review the results and recommendations of the research conducted by the Codex Ad Hoc Working Group on Protein Quality Measurement, and to evaluate the protein digestibility-corrected amino acid score method for its usefulness in assessing protein quality in human nutrition.

\section{Joint FAO/WHO Expert Consultation on Protein Quality Evaluation (1989)}

A Joint FAO/WHO Expert Consultation on Protein Quality Evaluation was held in Bethesda, MD from December 4 to 8,1989 . The objectives of the meeting were: to review present knowledge of protein quality assessment, to discuss various techniques used in assessing protein quality of foods, and to specifically evaluate amino acid score corrected for protein 
digestibility, the method recommended by CCVP. The report of the Joint FAO/WHO Expert Consultation ${ }^{(4)}$ was published in 1991. The Consultation concluded that PDCAAS was the most suitable regulatory method for assessing protein quality of foods and infant formulas. It was further concluded that since this method is based on human amino acid requirements, it is inherently more appropriate than animal assays employed for predicting protein quality of foods. Therefore the Consultation recommended that PDCAAS be adopted as the preferred method of measuring quality in reference to human nutrition. Other conclusions and recommendations of the Consultation are noted below ${ }^{(4)}$ :

\section{Amino acid analysis of foods}

(1) The Consultation recognized that significant advancements had been made in standardizing amino acid methodology for the determination of amino acids in a variety of foods.

(2) It noted that methods for the determination of amino acids in foods required three standardized hydrolyses including, acid hydrolysis of unoxidized protein for the determination of all amino acids except tryptophan, methionine and cystine; acid hydrolysis of oxidized protein for the determination of methionine and cystine; and alkaline hydrolysis of unoxidised protein for tryptophan $^{(8)}$, followed by separation and quantitation of the released amino acids by IEC using cation exchange resins and postcolumn derivatization (by a commercial amino acid analyzer or HPLC system) or by precolumn derivatization followed by reversed phase HPLC.

(3) The standardized amino acid analysis methods can provide data with a repeatability within laboratory of about $5 \%$ and reproducibility between laboratories of about $10 \%$ for most amino acids. This variability was considered acceptable for the purposing of calculating amino acid score.

(4) The need for further studies to standardise the hydrolytic and oxidation procedures and to improve accuracy of the procedures for further reduction in inter-laboratory variation was noted.

(5) The collaborative testing of the new HPLC methods was recommended.

(6) It was recommended that amino acid results should be reported as $\mathrm{mg}$ amino acid/g N or $\mathrm{mg}$ amino acid/g protein by using the nitrogen-to-protein conversion factor of $6 \cdot 25$. The uses of other food specific protein factors were not recommended.

(7) FAO should update their publication entitled "Amino Acid Content of Foods and Biological Data on Proteins" (FAO 1970) and commission new amino acid analyses of foods where there are insufficient data.

(8) Reliable national tables of amino acid composition of food products which have been clearly defined in terms of composition and processing should be developed.

\section{Amino acid requirements and scoring pattern}

(1) The Consultation recognized that the amino acid scoring pattern proposed in 1985 by $\mathrm{FAO} / \mathrm{WHO} / \mathrm{UNU}^{(24)}$ for children of preschool age was the most suitable pattern for use in the evaluation of dietary protein quality for all age groups, except infants.

(2) It noted that the amino acid profile of human milk should be the basis for the scoring pattern to assess protein quality in foods for infants less than 1 year of age.

(3) It also noted that the recommendation for the two amino acid scoring patterns to be used for infants and for all other ages must be considered as temporary until the results of further research either confirm their adequacy or demand a revision.

(4) It was recommended that further research must be carried out to confirm the currently accepted values of protein and amino acid requirements of infants and preschool children and to define the amino acid requirements of school-aged or adolescent children and of adults; and that $\mathrm{F} \mathrm{AO/WHO}$ coordinate international research programmes to determine human amino acid needs.

\section{Digestibility considerations}

(1) The Consultation noted the similarity in the ability of humans and rats to digest foods, and concluded that the true digestibility of crude protein is a reasonable approximation of the true digestibility of most amino acids (as determined by the rat balance method) in diets based on animal protein sources, cereals, oilseeds, legumes or mixture of protein sources. Therefore, it was recommended that amino acid scores be corrected only for the true digestibility of protein.

(2) The Consultation agreed that the rat balance method is the most suitable practical method for predicting protein digestibility by humans.

(3) It further recommended that research should be undertaken to compare protein digestibility values of humans and rats from identical foods.

(4) It recommended that further research be carried out to perfect and evaluate the most promising in vitro procedures for estimating protein digestibility; and when human balance studies cannot be used, the standardized rat faecal-balance method of Eggum ${ }^{(28)}$ or McDonough et $a l^{(27)}$ should be used.

(5) Digestibility determinations must be carried out for novel products or processes. However, established protein digestibility values of well-defined foods may be taken from a published data base for use in routine assessment of protein quality of foods by the amino acid scoring procedure, provided that all safety and toxicological criteria have been met. Moreover, a data base for protein digestibility of raw and processed products should be established.

(6) Further research was encouraged to perfect and evaluate the most promising in vitro methods for predicting 
protein digestibility such as those of Satterlee et $a l^{(29)}$ and Pederson and Eggum ${ }^{(30)}$.

(7) It was recognized that amino acid digestibility values obtained by the faecal method, are, for most amino acids in most food products, higher than those obtained by the ileal analysis method. In some studies, net synthesis of methionine and lysine has been reported to occur in the large intestine. Thus, depending on the amino acid and on the food, the amino acid digestibility values obtained by the faecal analysis method are overestimated (which is usually the case) or underestimated when compared to those obtained by the ileal analysis method. While it was recognised that faecal true digestibility of protein and amino acids has shortcomings, this method was considered still to be superior to the ileal analysis method. This is because of uncertainties in the contribution and variation of endogenous secretions at the terminal ileum.

\section{Overall recommendation of FAO/WHO 1991 Expert Consultation}

Based on the above conclusions, the Consultation agreed that the protein digestibility-corrected amino acid score method was the most suitable approach for routine evaluation of protein quality for humans and recommended the adoption of this method as an official method at the international level.

\section{Amino acid composition of human milk}

Use of the amino acid composition of human milk as the reference in calculating amino acid scores (as a predictor of protein quality) of infant formulas was recommended by $\mathrm{FAO} / \mathrm{WHO}^{(4)}$. Similarly, the European Commission $(\mathrm{EC})^{(31)}$ directive for composition of infant formulas includes a protein quality requirement based on amino acid or chemical score with human milk as the reference.

In calculating amino acid scores, the two groups have, however, suggested use of different values for several IAA in human milk. According to $\mathrm{EC}^{(31)}$, human milk contains $31 \%$ lower concentrations of methionine + cyst(e)ine $(29 \mathrm{mg} / \mathrm{g}$ protein) than those $(42 \mathrm{mg} / \mathrm{g}$ protein) reported by $\mathrm{FAO} / \mathrm{WHO} / \mathrm{UNU}^{(24)}$ and subsequently endorsed by $\mathrm{FAO} / \mathrm{WHO}^{(4)}$. Similarly, the values $(\mathrm{mg} / \mathrm{g}$ protein) for valine ( 45 vs. 55 ), phenylalanine + tyrosine (66 vs. 72 ), isoleucine ( 40 vs. 46), and leucine (85 vs. 93) reported by $\mathrm{EC}^{(31)}$ are $9-18 \%$ lower than those reported by $\mathrm{FAO} / \mathrm{WHO}^{(4)}$. The differences for other IAA in human milk as reported by the two groups $\left(\mathrm{EC}^{(31)}\right.$ vs. FAO/WHO $\left.{ }^{(4)}\right)$ are relatively small: histidine, 25 vs. 26; lysine, 67 vs. 66; threonine, 44 vs. 43; and tryptophan, 17 vs. $17 \mathrm{mg} / \mathrm{g}$ protein.

To resolve these differences in the estimated amino acid composition of human milk specified by the two groups, literature reports using accurate and standardised methodologies have been reviewed (Table 1 ). Based on the average of the 12 studies noted in Table 1, human milk contained ( $\mathrm{mg} / \mathrm{g}$ protein): histidine, 25; isoleucine, 87; leucine, 101; lysine, 70; methionine, 14; cystine, 25; phenylalanine, 47; tyrosine, 44; threonine, 48; tryptophan, 19; and valine, 59. A comparison of these values with those reported by $\mathrm{FAO} / \mathrm{WHO}^{(4)}$ and $\mathrm{EC}^{(31)}$ revealed that the literature reports would support the use of the $\mathrm{FAO} / \mathrm{WHO}^{(4)}$ values for predicting the protein quality of infant formulas (Table 2). It would also suggest revision of the values for the total sulphur amino acids, valine, phenylalanine + tyrosine, isoleucine, leucine, and threonine, as recommended by $\mathrm{EC}^{(31)}$ for routine protein quality assessment.

The use of combined sulphur amino acid (cysteine + methionine) and aromatic amino acid (phenylalanine + tyrosine) content remains the recommended approach for computing amino acid scores of infant formulas by $\mathrm{FAO} / \mathrm{WHO}^{(4)}, \mathrm{EC}^{(31)}$ and $\mathrm{LSRO}^{(42)}$. A review of the literature of the amino acid composition of human milk would, however, suggest the need to include a desirable cysteine/ methionine ratio in the scoring pattern. Results of the twelve studies reported in Table 1 would indicate that the most suitable cysteine/methionine ratio (molar basis) may be about $2 \cdot 0$. The $\mathrm{LSRO}^{(40)}$ report also advised that instead of

Table 1. Selected published values for the dietary indispensable amino acid* composition ( $\mathrm{mg} / \mathrm{g}$ protein) of human milk

\begin{tabular}{|c|c|c|c|c|c|c|c|c|c|c|c|}
\hline References & His & Ile & Leu & Lys & Met & Cys & Phe & Tyr & Thr & Trp & Val \\
\hline Atkinson \& Lonnerdal ${ }^{(32)}$ & 28 & 52 & 93 & 58 & 12 & 18 & 34 & 42 & 42 & 12 & 49 \\
\hline Darragh \& Moughan ${ }^{(33)}$ & 31 & 66 & 67 & 82 & 18 & 35 & 49 & 49 & 64 & ND & 66 \\
\hline Davis et al. ${ }^{(34)}$ & 23 & 51 & 93 & 58 & 12 & 18 & 34 & 42 & 42 & ND & 49 \\
\hline Janas et al. ${ }^{(35)}$ & 18 & 48 & 95 & 60 & 11 & 30 & 30 & 29 & 38 & 13 & 61 \\
\hline Nayman et al. ${ }^{(36)}$ & 25 & 60 & 114 & 73 & 17 & 27 & 43 & 47 & 51 & 23 & 64 \\
\hline Rigo et al. ${ }^{(37)}$ & 40 & 59 & 112 & 82 & 14 & 17 & 54 & 58 & 54 & 27 & 59 \\
\hline Sarwar et al. ${ }^{(38)}$ & 23 & 50 & 106 & 74 & 13 & 24 & 42 & 47 & 56 & 18 & 61 \\
\hline Svanberg et al. ${ }^{39} \dagger$ & 23 & 79 & 128 & 66 & 13 & 26 & 37 & 39 & 45 & 21 & 56 \\
\hline Svanberg et al. ${ }^{39} \ddagger$ & 24 & 53 & 102 & 66 & 13 & 25 & 36 & 38 & 46 & 21 & 58 \\
\hline UK Health ${ }^{(40)}$ & 23 & 51 & 93 & 69 & 14 & 19 & 37 & 29 & 44 & 22 & 66 \\
\hline Villalpando et al. ${ }^{(41} \S$ & 21 & 64 & 105 & 79 & 14 & 26 & 85 & 58 & 47 & 17 & 63 \\
\hline Villalpando et al. ${ }^{(41}$ q & 22 & 55 & 102 & 71 & 18 & 32 & 79 & 56 & 48 & 21 & 55 \\
\hline Grand mean & 25 & 57 & 101 & 70 & 14 & 25 & 47 & 44 & 48 & 19 & 59 \\
\hline
\end{tabular}

*The three-letter abbreviations for amino acids (His, histidine; lle, isoleucine; Leu, leucine; Lys, lysine; Met, methionine; Cys, cystine; Phe, phenylalanine; Tyr, tyrosine; Thr, threonine; Trp, tryptophan; Val, valine) are used in this Table. †Swedish subjects.

$\ddagger$ Ethiopian subjects.

$\S$ Texan subjects.

ๆ Otomi (rural Mexican) subjects. 
Table 2. A comparison of the dietary indispensable amino acid profiles of human milk as specified by the European Commission (EC) and $\mathrm{FAO} / \mathrm{WHO}$ with literature values (average of the 12 studies noted in Table 1)

\begin{tabular}{lccc}
$\begin{array}{l}\text { Amino acid* } \\
\text { (mg/g protein) }\end{array}$ & EU $^{(31)}$ & FAO/WHO $^{(4)}$ & Average of 12 studies \\
\hline His & 25 & 26 & $25(24) \dagger$ \\
Ile & 40 & 46 & $57(56)$ \\
Leu & 85 & 93 & $101(100)$ \\
Lys & 67 & 66 & $70(69)$ \\
Met + Cys & 29 & 42 & $39(39)$ \\
Phe + Tyr & 66 & 72 & $91(88)$ \\
Thr & 44 & 43 & $48(41)$ \\
Trp & 17 & 17 & $19(\mathrm{ND})$ \\
Val & 45 & 55 & $59(53)$
\end{tabular}

* The three-letter abbreviations for amino acids (His, histidine; Ile, isoleucine; Leu leucine; Lys, lysine; Met, methionine; Cys, cystine; Phe, phenylalanine; Tyr, tyrosine; Thr, threonine; Trp, tryptophan; Val, valine) are used in this Table.

† Values in brackets are corrected for the true ileal digestibility of amino acids as determined in piglets fed mature human milk ${ }^{(33)}$.

only one amino acid theoretically supplying the total combined amount, the ratio of the relevant amino acids should be within the range $1: 2$ to $2: 1$ based on approximate unit ratios in human milk, and should be used until adequacy of other ratios is tested.

The gross amino acid profile of human milk is used as a standard for determining the amino acid requirements of the infant. This is based on the assumption that the amino acids in human milk are completely absorbed by the infant ${ }^{(24)}$. Since significant amounts of intact immune proteins have been found in the faeces of breast-fed infants, it has been suggested that several of the proteins in human milk resist digestion $^{(43)}$. The digestible protein in human milk could be determined by including a correction for the faecal immune proteins ${ }^{(44)}$. The faecal method for determining amino acid digestibility, however, leads to overestimation of digestible amino acids, because of a significant microbial breakdown of protein in the large intestine ${ }^{(45)}$. The true ileal digestibility of amino acids in human milk in the piglet model which would appear to be a suitable animal model for studying aspects of protein digestion in human infants have been determined ${ }^{(33)}$. The true digestibility of amino acids in human milk ranged from $81-101 \%$ with threonine (86\%) being the least digestible IAA. These amino acid digestibility data were used in correcting the average gross amino acid composition of human milk in Table 2. The differences between the corrected amino acid composition of human milk based on the 12 published studies and of that specified by $\mathrm{FAO} / \mathrm{WHO}^{(4)}$ were very small (less than $10 \%$ in the case of histidine, leucine, lysine, methionine + cystine, threonine and valine. The values recommended by $\mathrm{FAO} / \mathrm{WHO}^{(4)}$ were 22, 21 and $12 \%$ lower compared to those based on the average of literature reports for isoleucine, phenylalanine + tyrosine and tryptophan, respectively. Taking into account the interlaboratory variability of about $10 \%$ in amino acid determination, the real differences between the literature reports and $\mathrm{FAO} / \mathrm{WHO}^{(4)}$ data for amino acid composition of human milk may be small.
San Francisco conference on protein quality measurement (1999)

The criteria and significance of dietary protein sources were addressed at an international symposium held in San Francisco, CA on October 4, 1999, and the following recommendations were considered appropriate ${ }^{(7)}$ :

(1) The FAO/WHO/UNU 1985 amino acid scoring pattern ${ }^{(24)}$ for the adult significantly underestimates the indispensable amino acid (IAA) requirements. This was also the conclusion of the $\mathrm{FAO} / \mathrm{WHO}^{(4)}$ report that proposed, as an interim procedure, the use of the $\mathrm{FAO} / \mathrm{WHO} / \mathrm{UNU}^{(24)}$ amino acid requirement pattern for preschool children to score dietary proteins for all age groups except infants. Research conducted since that time has continued to support the general validity of this proposal. Therefore, it was recommended that a new United Nations consultation be convened to review and establish an updated international scoring pattern for protein quality evaluation.

(2) The PDCAAS procedure appears to be generally accepted as a routine method for protein quality assessment. However, it is time to revisit and evaluate this method in more detail. Major points that require attention include the measurements of digestibility of protein, appropriateness of the truncation of the score of high quality proteins downward (from $>100$ to 100 ), and the inclusion in a scoring index of a value that indicates the capacity of individual protein sources to complement protein sources that are deficient in specific IAA. The use of ileal rather than faecal digestibility as a basis for the scoring procedure as well as determining whether protein digestibility represents a valid indicator of the bioavailability of the limiting amino acid (s) must be addressed.

(3) The PDCAAS should be further validated and tested as a routine procedure through a comparison with other approaches, including in vivo studies of dietary protein utilization in humans. The deposition of nitrogen during the prandial phase appears to be a critical factor in determining food protein quality, and this might be used to help discriminate significant differences among dietary proteins.

FAO/WHO Working Group on analytical issues regarding protein, protein quality and food labelling (2001)

Since its adoption by $\mathrm{FAO} / \mathrm{WHO}^{(4)}$ in 1991 , the PDCAAS method has been widely accepted. However, the method has been criticised for a number of reasons. In 2001, the FAO/WHO Working Group ${ }^{(6)}$ on "Analytical Issues Related to Food Energy \& Protein, Protein Quality \& Food Labelling" assessed the validity of criticisms of PDCAAS since its use for the past ten years. These criticisms of the PDCAAS method included the following:

\section{The PDCAAS method does not credit extra nutritional value of high quality proteins:}

Since scores $>100$ are considered to be 100 , the PDCAAS method does not credit the extra nutritional value of a protein 
having a score higher than that of the reference protein such as egg, fish, milk and most meat protein products. This point was not adequately discussed at the $\mathrm{FAO} / \mathrm{WHO}^{(4)}$ Expert Consultation in 1991.

The PER and PDCAAS values of a number of selected animal food products are compared in Table 3. As can be noted in this comparison, the PER method does give credit to the extra nutritional value high quality animal proteins by giving them a value higher than $2 \cdot 5$. The PDCAAS method, however, fails to recognize the additional value of high quality animal protein products. For example, comparison of the nontruncated PDCAAS values of the food protein sources have been reported to be: milk $>$ soya $>$ pea $>$ wheat with values of 120 (sulphur amino acids), 99 (sulphur amino acids), 73 (sulphur amino acids) and 36 (lysine), respectively $^{(7)}$. For comparison, measurements of the efficiency of postprandial nitrogen retention for these foods in humans were in this exact order ${ }^{(49)}$. Therefore, there is a need to revise the calculation of PDCAAS to permit values $>100$ for high quality proteins, especially if they are intended to be used as supplements to other low quality proteins. However, this revision may not be required to calculate the PDCAAS for protein mixtures, where the supplemental excess of amino acids is included in the calculation. Moreover, this revision would be of no practical consequence for sole source foods. Protein quality assessment should ideally take into account the ability of the protein to satisfy nitrogen and amino acid requirements when fed as the sole or principal source of protein and the capacity of the protein source to complement another protein source deficient in one or more individual amino acids ${ }^{(7)}$. Milk or meat proteins can fully satisfy all IAA requirements even when fed as the sole source at a level of $0 \cdot 7 / \mathrm{kg} / \mathrm{d}$. In this case, the amino acid score would be 100 . Moreover, milk or most other animal proteins serve as a rich source of lysine, threonine and the sulphur amino acids. Therefore, these protein sources would be complementary for lysine-, methionine + cystine- or threonine-deficient protein sources. It may be appropriate to identify the score for milk proteins as 128,123 or 120 for lysine, threonine and methionine + cystine, respectively ${ }^{(7)}$

\section{The PDCAAS method overestimates protein quality of products containing antinutritional factors}

It has been suggested that PDCAAS may be inappropriate for predicting the protein quality of sources containing naturally occurring growth-depressing factors or antinutritional factors formed during processing ${ }^{(46,47,50-52)}$. A comparison of the PDCAAS based on rat amino acid requirements and the RPER or RNPR indicated that the scoring method clearly overestimated protein quality of those products which contained antinutritional factors such as mustard flour (PDCAAS of $84 \%$ vs. RPER or RNPR of 0), raw black beans (PDCAAS of $45 \%$ vs. RPER or RNPR of 0), alkaline-treated lactalbumin (PDCAAS of $55 \%$ vs. RPER or RNPR of 0 ), alkaline-treated SPI (PDCAAS of $44 \%$ vs. RPER or RNPR of 0 ) and overheated skim milk powder (PDCAAS of 29\% vs. RPER/RNPR of 0-5\%) (Table 4). The overestimation of the protein quality of these
Table 3. PER (Protein Efficiency Ratio) and PDCAAS (Protein Digestibility-corrected Amino Acid Score) values for some high quality animal protein products.

\begin{tabular}{|c|c|c|c|}
\hline Product & $\begin{array}{c}\text { PER } \\
(\text { Casein }=2.5)\end{array}$ & $\begin{array}{l}\text { PDCAAS } \\
(\%)\end{array}$ & References \\
\hline Casein + Met & $3 \cdot 1$ & 100 & Sarwar ${ }^{(46)}$ \\
\hline $\begin{array}{l}\text { Whey protein } \\
\text { concentrate }\end{array}$ & 3.0 & 100 & Fenwick et al. ${ }^{(47)}$ \\
\hline Egg white solids & 3.0 & 100 & Sarwar et al. ${ }^{(15)}$ \\
\hline Lactalbumin & 2.8 & 100 & Sarwar ${ }^{(46)}$ \\
\hline Skim milk powder & $2 \cdot 8$ & 100 & Mitchell et al. ${ }^{(48)}$ \\
\hline Milk protein isolate & $2 \cdot 8$ & 100 & Fenwick et al. ${ }^{(47)}$ \\
\hline Minced beef & $2 \cdot 7$ & 100 & Sarwar et al. ${ }^{(15)}$ \\
\hline Beef Salami & $2 \cdot 6$ & 100 & Mitchell et al. ${ }^{(48)}$ \\
\hline Tuna & $2 \cdot 6$ & 100 & Mitchell et al. ${ }^{(48)}$ \\
\hline
\end{tabular}

protein sources by the PDCAAS method was even more marked when the score was calculated based on human amino acid requirements (Table 4). Some of these protein products contain naturally occurring growth-depressing factors such as glucosinolates and isothiocyanates (breakdown products of glucosinolates) in mustard flour ${ }^{(47)}$ and trypsin inhibitors and hemagglutinins in raw black beans and raw $\mathrm{SBM}^{(50)}$. Some other protein products contain antinutritional factors formed during alkaline and/or heat treatments such as lysinoalanine (LAL) in alkaline/heat-treated lactalbumin and $\mathrm{SPI}^{(51,53)}$, and Maillard reaction compounds in overheated skim milk powder ${ }^{(52)}$.

\section{The PDCAAS method does not take into account bioavailability of amino acids}

In reviewing digestibility data, the $\mathrm{FAO} / \mathrm{WHO}^{(4)} 1991$ report revealed that differences between the digestibility of protein and most of the IAA in animal protein sources, and lowfibre cereals and oilseeds were less than $10 \%$. However, the digestibility of protein was not a good predictor of the bioavailability of limiting amino acids in grain legumes. In beans, peas, and lentils, values for the digestibility of methionine, cystine and tryptophan were as much as 43, 44 and 35\% lower than those of protein, respectively ${ }^{(54)}$. The large differences between the digestibility of protein and limiting amino acids such as methionine, cystine and tryptophan in beans, peas and lentils would suggest that PDCAAS would overestimate the protein nutritional quality of grain legumes, and in these cases, amino acid score would have to be corrected for the bioavailability of the limiting IAA.

The PDCAAS method overestimates the quality of poorly digestible proteins supplemented with limiting amino acids, and of proteins co-limiting in more than one amino acid

The PDCAAS method assumes complete biological efficiency of supplemental amino acids in improving protein quality which may not be true, especially in the case of low quality proteins ${ }^{(46,55)}$. The PDCAAS and RNPR values for zein (a protein of low digestibility and poor quality) were 9 and 
Table 4. Effect of processing treatments on protein digestibility-corrected amino acid scores (PDCAAS), relative protein efficiency ratio (RPER), relative net protein ratio (RNPR) and true protein digestibility (TPD) values for several protein products*

\begin{tabular}{|c|c|c|c|c|c|}
\hline Product & PDCAAS (Rat) & PDCAAS (Human) & RPER & RNPR & TPD \\
\hline Casein + Methionine & 100 & 100 & 100 & 100 & 100 \\
\hline Casein & 85 & 100 & 80 & 84 & 99 \\
\hline Lactalbumin & 100 & 100 & 89 & 91 & 99 \\
\hline Lactalbumin, treated $\dagger$ & 55 & 67 & 0 & 0 & 73 \\
\hline Skim milk & 74 & 100 & 77 & 82 & 94 \\
\hline Skim milk, heated & 29 & 31 & 0 & 5 & 77 \\
\hline Soya protein isolate (SPI) & 62 & 100 & 56 & 64 & 96 \\
\hline SPI, treated $†$ & 44 & 49 & 0 & 0 & 68 \\
\hline Soyabean meal, raw & 58 & 80 & 27 & 44 & 80 \\
\hline Soyabean meal, heated & 58 & 83 & 63 & 70 & 83 \\
\hline Black beans, raw & 45 & 72 & 0 & 0 & 71 \\
\hline Black beans, heated & 51 & 84 & 18 & 35 & 83 \\
\hline Mustard flour & 84 & 92 & 0 & 0 & 92 \\
\hline Zein & 1 & 1 & 0 & 0 & 63 \\
\hline Zein + Amino acids $\ddagger$ & 63 & 71 & 3 & 44 & 73 \\
\hline
\end{tabular}

$11 \%$, respectively. When the zein diet was supplemented with lysine, tryptophan and methionine, the PDCAAS and RNPR values were 81 and $30 \%$, respectively ${ }^{(46)}$. A marked difference between the PDCAAS and RPER or RNPR of amino acidsupplemented zein (Table 4) would suggest incomplete biological efficiency of the supplemental amino acids. The poor biological response to amino acid supplemented zein may have been due to the poor bioavailability of IAA other than those supplemented which may not be $100 \%$.

The PDCAAS method would also be inaccurate for predicting the quality of proteins co-limiting in more than one essential amino acid such as those in soya-based infant formulas (Table 5). A comparison of IAA compositions of four soyabased infant formulas with that of human milk $\left(\mathrm{FAO} / \mathrm{WHO}^{(4)}\right)$ indicated that the formulas (supplemented with methionine) were still lower in sulphur amino acids than human milk. The soya-based formulas were also marginally deficient in tryptophan, threonine, lysine, leucine and valine when compared to human milk. Since the identification of the true first limiting amino acid would be difficult in such cases, an improvement in protein quality with supplementary amino acids (s) should not be assumed without biological testing. In such cases, the assumed efficiency of supplementary amino acid (s) must be confirmed biologically (Tables 5 and 6).

We have determined PDCAAS values of commercial soyabased infant formulas sold in Canada ${ }^{(56)}$. All the soya-based infant formulas had been supplemented with methionine. The PDCAAS values (using the $\mathrm{FAO} / \mathrm{WHO}^{(4)}$ scoring pattern for human milk) of the soya-based formulas ranged from $56-76 \%$. In practice, the lower protein quality of infant formulas is compensated for by the higher level of total protein (g/100 kcal) in soya-based infant formulas compared to human milk (2.65-3.68 vs. 1.5). Thus, no evidence of amino acid deficiency is observed in clinical studies.

After addressing the above-noted criticisms of the PDCAAS method, the FAO/WHO ${ }^{(5)}$ Working Group made the following recommendations:

(1) Two distinct uses of protein quality data, including assessment of human protein and amino acid requirements; and of protein adequacy of foods and food products sold to consumers for regulatory purposes, should be recognized;

Table 5. Dietary indispensable amino acids in four commercial soya-based infant formulas sold in Canada (expressed as a proportion of the respective amino acids in the $\mathrm{FAO} / \mathrm{WHO}^{(4)}$ human milk reference amino acid pattern)*

\begin{tabular}{lcccc}
\hline Amino acid (\%) & Formula-A & Formula-B & Formula-C & Formula-D \\
\hline Histidine & 106 & 89 & 98 & 92 \\
Isoleucine & 104 & 100 & 102 & 98 \\
Leucine & 87 & 85 & 87 & 82 \\
Lysine & 84 & 87 & 85 & 81 \\
Methionine + cystine & 70 & 71 & 79 & 83 \\
Phenylalanine + tyrosine & 127 & 120 & 125 & 124 \\
Threonine & 85 & 84 & 87 & 90 \\
Tryptophan & 78 & 72 & 70 & 87 \\
Valine & 88 & 85 & 86 & 85 \\
\hline
\end{tabular}

* Gilani GS, unpublished data. 
Table 6. Protein Digestibility-corrected Amino Acid Score, Relative Protein Efficiency Ratio (RPER) and Serum Urea Nitrogen (SUN) values for four soya-based infant formulas*

\begin{tabular}{|c|c|c|c|}
\hline Product & $\begin{array}{c}\text { PDCAAS } \\
(\%)\end{array}$ & $\begin{array}{c}\text { RPER } \\
(\%)\end{array}$ & $\begin{array}{c}\text { SUN } \\
(\mathrm{mg} / 100 \mathrm{ml})\end{array}$ \\
\hline Formula-A & 66 & 71 & 7.52 \\
\hline$+\operatorname{Met}(0.2 \%)$ & 73 & 74 & $6 \cdot 67$ \\
\hline + Lys $(0.2 \%)$ & 66 & 73 & $6 \cdot 10$ \\
\hline$+\operatorname{Thr}(0.1 \%)$ & 66 & 80 & 7.55 \\
\hline$+\operatorname{Trp}(0.05 \%)$ & 66 & 73 & $6 \cdot 67$ \\
\hline + Four amino acids & 80 & 99 & 2.37 \\
\hline Formula-B & 67 & 79 & $8 \cdot 77$ \\
\hline+ Met $(0.2 \%)$ & 68 & 88 & 6.77 \\
\hline+ Lys $(0.2 \%)$ & 67 & 79 & 6.47 \\
\hline$+\operatorname{Thr}(0.1 \%)$ & 67 & 79 & $7 \cdot 27$ \\
\hline$+\operatorname{Trp}(0.05 \%)$ & 67 & 82 & $8 \cdot 20$ \\
\hline + Four amino acids & 81 & 100 & 2.37 \\
\hline Formula-C & 66 & 81 & $9 \cdot 70$ \\
\hline+ four amino acids & 81 & 100 & $2 \cdot 15$ \\
\hline Formula-D & 77 & 74 & 9.88 \\
\hline + Four amino acids & 78 & 100 & $2 \cdot 67$ \\
\hline
\end{tabular}

(2) Amino acids should be treated as individual nutrients, and the ultimate evaluation of the nutritional value of protein foods should be made from amino acid data in comparison to the requirements. This would require the use of adjustments for the digestibility of protein and/or amino acids, and their availability;

(3) There are sufficient data on the digestibility of protein in foods and these should be compiled. However, there are insufficient information on the bioavailability (digestibility) of amino acids. Until sufficient data on digestible amino acids in foods become available, inclusion of correction for protein digestibility would serve a useful nutritional purpose in predicting information on the levels of digestible amino acids. This would indicate the capacity of individual protein sources to complement protein sources that are deficient in specific IAA;

(4) Until data on digestible amino acids in foods become available, digestibility of protein should be considered as a good approximation of the bioavailability of amino acids in mixed human diets based on properly processed (containing minimal amounts of residual antinutritional factors) and highly digestible proteins. In such cases, the PDCAAS method should be the preferred method for routine prediction of protein quality;

(5) The PDCAAS method may be inappropriate for the routine prediction of protein quality of sole source foods such as infant formulas and enteral nutritionals and novel protein sources which contain high levels of known antinutritional factors, both occurring naturally or those formed during processing. Since high levels of antinutritional factors may adversely impact on digestibility of amino acids and utilisation of protein, the use of the PDCAAS method would overestimate protein quality of products containing these factors. There is a need to establish upper safe limits of antinutritional factors;
(6) For regulatory uses, the PDCAAS method is also inappropriate for prediction of protein quality of high quality proteins because it fails to recognize their nutritional value as supplements to other low quality proteins, Therefore, the PDCAAS method should be revised to permit values of more than 100 for high quality proteins;

(7) To improve accuracy and to further reduce interlaboratory variation in amino acid analysis, additional studies should be undertaken to standardize the hydrolytic and oxidation procedures. Collaborative studies should be undertaken of the extensively used HPLC methods for the determination of amino acids such as the precolumn derivatization with PITC (phenylisothiocyanate). Moreover, an official standardised method for the determination of amino acids in foods and faeces and digesta should be developed;

(8) Research should be undertaken to compare ileal amino acid digestibility values of humans and animal models from identical foods. In addition, standardised ileal digestibility procedures should be developed and sufficient data on foods should be generated to facilitate replacement of the faecal method by the ileal method;

(9) The 1970 FAO Publication, "Amino Acid Contents of Foods and Biological Data on Proteins" should be revised with new data and additional information on nitrogen-to-protein conversion factors and amino acid digestibility values where applicable;

(10) The above-noted recommendations for revision, further compilation of data and further research would improve the usefulness of the PDCAAS method and/or suggest new suitable in vitro or biological assays for the routine prediction of protein quality of foods which would be applicable to the entire range of foods used in human nutrition.

\section{Overall recommendation}

In view of the shortcomings of the PDCAAS method as noted above, it has been recommended that a new FAO/WHO expert consultation on protein quality evaluation be convened to re-examine the validity of the PDCAAS method for the routine protein quality assessment of foods, and to suggest appropriate revisions and/or adoption of a biological assay which would be applicable to the entire range of foods used in human diets.

In addition to the above recommendations, the FAO/ $\mathrm{WHO}^{(5)}$ Working Group also addressed the following issues:

\section{Nitrogen-to-protein conversion factors}

The quantification of total protein content is a common laboratory procedure, and its accuracy is essential for many food and feed applications including protein $(\mathrm{N})$ requirements, protein quality assessment by the PDCAAS method and other assays, nutritional labelling and international trade for protein products.

The Kjeldahl method for determination of organic $\mathrm{N}$ is a widely accepted procedure. However, the selection of the 
appropriate nitrogen-to-protein conversion factor (N: P factor) for calculating the total protein content has been a matter of controversy, and practices are not consistent among laboratories. Since most animal proteins contain $16 \% \mathrm{~N}$, an N: P factor of 6.25 is commonly used to give a reasonable estimate of protein content. Some proteins contain a higher or lower percentage of $\mathrm{N}$ and some foods also contain non-protein $\mathrm{N}$. The $\mathrm{N}$ content of a range of proteins has been measured and conversion factors derived for many food proteins ${ }^{(57)}$. The factors for wheat, wheat flour or pasta; wheat bran; rice; rye, barley or oats; groundnuts; soyabeans, soyabean flour or products; sesame, sunflower or safflower seeds were $5 \cdot 30-5 \cdot 83$, while that for milk or cheese was $6 \cdot 38$. The use of specific N: P factors would allow a more precise comparison of the amino acid composition of foods. Similarly, an $\mathrm{N}$ : P Conversion factor Committee of the AOAC reaffirmed the continued use of a set of factors compiled by USDA ${ }^{(58)}$ as reprinted in Method 14.068 in $\mathrm{AOAC}^{(59)}$.

In proteins, amino acids are linked by peptide bonds. The elements of water are added to each molecule during hydrolysis, so that the recovery of amino acids should be greater than $100 \%$. To get a true picture of the relationship of $\mathrm{N}$ to amino acids, the amino acid values from hydrolysates must be corrected to the original residue form in which they exist in proteins. Therefore, the N: $\mathrm{P}$ factors derived from the ratios of total amino acid residues (sum of molecular weight of each amino acid less the molecular weight of $\mathrm{H}_{2} \mathrm{O}$ ) to amino acid $\mathrm{N}$ (AAN) in a protein should provide the most reliable conversion factors ${ }^{(60)}$. The quantitative amino acid compositions and true N: P factors for 23 animal and plant foods were determined $^{(61)}$. The $\mathrm{N}$ : $\mathrm{P}$ factors ranged from 6.02 to 6.15 for dairy products, from 5.61 to 5.93 for egg, meat, fish and cereal products and from 5.14 to 6.26 for legume, root, tuber, vegetable, fruit, and microbial foods. The average N: $\mathrm{P}$ factor for the 23 foods was $5 \cdot 68 \pm 0 \cdot 30$, and a common $\mathrm{N}$ : P factor of 5.70 was recommended for use in all mixed or blended foods or diets where accurate protein values are required for nutrition applications ${ }^{(61)}$.

After discussing the possible disbandment of a common factor of 6.25 in favour of the use of accurate nitrogen-toprotein conversion factors for various foods, the FAO/ $\mathrm{WHO}^{(5)}$ Working Group pointed out that this aspect seemed more important for regulatory and labelling issues, while not so relevant for determining overall requirements when related to mixed diets. When dealing with mixed diets, a factor of 6.25 seems valid. When dealing with sole source foods such as infant formulas, more precision may be required.

\section{Global adaptability of the PDCAAS method}

The initial cost incurred when setting up the technology to determine PDCAAS in developing countries may be high. But once this is done, the PDCAAS method is rapid and the supplies are relatively available and inexpensive provided established digestibility values of well defined foods may be taken from published data for use in the amino acid scoring procedure, assuming all safety and toxicological criteria have been met. If a biological assay is required to determine the protein digestibility of a novel product or process, then the PDCAAS method may be more costly than PER.

\section{Special digestibility considerations for heat-treated or stored products}

It has been recognized that conventional true ileal amino acid digestibility values do not provide accurate results for some amino acids such as lysine in foods that have undergone heat processing or prolonged storage ${ }^{(62,63)}$. During processing or prolonged storage, the $\varepsilon$-amino group of lysine can react with other compounds (i.e., Maillard type reactions) to render the amino acid nutritionally unavailable. Some of these reacted lysine derivatives are acid labile and therefore can revert back to lysine, during the acid hydrolysis step used in conventional amino acid analysis, leading to an overestimation of the lysine content and digestible lysine; as the digestibility of lysine might be underestimated using the conventional true ileal digestibility assays ${ }^{(61)}$. This assay must be modified to account for damage to heat-sensitive amino acids. In such cases, other methods such as the true ileal reactive lysine digestibility assay ${ }^{(63)}$ are required to give accurate results.

\section{WHO/FAO/UNU Expert Consultation on Protein and Amino Acid Requirements in Human Nutrition (2002)}

To build on the work of several earlier consultations and meetings, the Joint WHO/FAO/UNU Expert Consultation on Protein and Amino Acid Requirements was held at WHO headquarters from April 9 to 16, 2002. The primary objectives of this Consultation were: "to review, advise and update protein and amino acid requirements for all age groups (infants, children, adolescents, adults, elderly), and for women during pregnancy and lactation; to review and develop recommendations on protein requirements in health and disease, including their implications for developing countries; to develop recommendations on protein quality and labelling, with respect to new requirement levels, for use worldwide and in the Codex Alimentarius". The report of the Consultation was published in $2007^{(6)}$.

After discussing the recommendations of the FAO/WHO 2001 Working Group ${ }^{(5)}$, the WHO/FAO/UNU ${ }^{(6)}$ Expert Consultation endorsed the PDCAAS method with minor modifications to the calculation method but also raised the following concerns about the method:

In previous reports, scoring patterns were calculated by dividing amino acid requirement values by the safe level of protein intake. However, scoring patterns that have been suggested since have been based on amino acid requirement values, which generally reflect best estimates of average requirements. This approach is supported by the values derived by Hegsted ${ }^{(64)}$ from his regression analysis of nitrogen balance data. Therefore, in the $2007 \mathrm{WHO} / \mathrm{FAO} / \mathrm{UNU}^{(6)}$ report, scoring patterns were based on amino acid requirement values divided by the mean protein requirement. 
New scoring patterns were proposed for four age groups including infants, preschool children (1-2 y), older children and adolescents (4-18 y), and adults ( $>18 \mathrm{y}$ )

A second concern related to correction for faecal as opposed to ileal protein digestibility in the calculation of PDCAAS. Based on literature reports ${ }^{(65,66)}$ about practically important ileo-faecal differences in monogastric animals like pigs and the general applicability of these observations to humans, it was recommended that while faecal digestibility is likely to remain the appropriate measure of overall nitrogen digestibility, it is unlikely to be a true measure of amino acid digestibility. It was further recommended that measurements at the ileal level would provide better measurements of amino acid digestibility and losses of both dietary and endogenous origin. Moreover, the recycling of intestinal nitrogen and bacterial amino acids to the body was identified as a complementary and unresolved issue.

A third concern related to the reduced bioavailability of some amino acids, such as lysine, which have been chemically transformed during the processing of foods. It was noted that the correction for protein digestibility in the calculation of PDCAAS values may not account for this reduction in bioavailability. Therefore, the need to have a specific assay to measure accurate lysine digestibility in such cases was recognized. A specific assay ${ }^{(65)}$ for "reactive" lysine, which should distinguish it from biologically unavailable lysine that has undergone Maillard reactions, was considered suitable in such cases.

A fourth important and controversial concern related to truncation of the amino acid score and consequent PDCAAS value. It was argued that truncation removes any differences between two proteins such as milk and soya, although actual concentrations of important IAA, which may be limiting in some diets, are higher in milk compared to soya. This could be recognized by giving individual protein sources an amino acid score of $>1$ or 100 . In the FAO/WHO 1991 report $^{(4)}$, truncation was not used for calculating amino acid scores but was applied to the calculation of PDCAAS value, and this created considerable confusion.

The PDCAAS value should predict the overall efficiency of protein utilization based on its two components, digestibility and biological value (BV; utilized nitrogen divided by digestible nitrogen). The principle behind this approach is that utilization of any protein will be first limited by digestibility, which determines the overall dietary amino acid nitrogen, and BV describes the competence of the absorbed amino acids to meet the metabolic demand. For any amount of absorbed nitrogen the best that can be achieved is that the amino acid pattern is an exact match of requirements, so that all amino acids are utilized. Therefore, BV can never exceed 1 or 100 . Similarly, a PDCAAS value of $>1$ or 100 would never be used.

It was noted that while amino acid score is calculated only from the content of IAA, the metabolic demand is for both IAA and non-essential nitrogen. Therefore, when any or all dietary IAA are present in excess of the demand, the absorbed mixture is unbalanced and limited by dispensable amino acids. It is assumed that dispensable amino acids could be supplied from the surplus IAA. If such conversion occurs, then all of the absorbed nitrogen will be utilized in the same way as that of an absorbed mixture that exactly matches the demand. On this assumption, it may be concluded that there can be no benefit from an amino acid score $>1$ or 100 with the theoretical possibility of a disadvantage if inter-conversions of IAA to dispensable amino acids were not complete.

These arguments should be carefully considered for calculating amino acid scores and PDCAAS $>1$ or 100 for food protein sources and diets. The argument for having non-truncated values of the amino acid score for individual protein sources is based on the advantage of identifying proteins as rich sources of IAA that can be used to complement other sources that are deficient in IAA. The fact that this could only be done in relation to amino acid score was not made clear in the FAO/WHO 1991 report $^{(4)}$ which incorrectly listed several proteins with PDCAAS values greater than their digestibility when the amino acid score was $>1$ or 100 . For example, the PDCAAS value for soyabean protein concentrate was listed as 0.99 (or 99\%) which was calculated from protein digestibility and amino acid score of 95 and 1.04 (or 104\%), respectively. This implies that its slight excess of IAA could compensate for the loss of $5 \%$ of total nitrogen during digestion and absorption which is arguably not correct. On the basis that protein digestibility is first limiting, the PDCAAS value should be calculated from a truncated amino acid score, the PDCAAS value for soyabean protein concentrate would be 0.95 (or 95\%), the same as its protein digestibility.

The calculation of the amino acid score for a dietary protein mixture, especially when the digestibility of the individual proteins varies also needs clarification. In this case, amino acid score is calculated for the mixture from its overall amino acid profile without identifying the score of component proteins. Based on the principle that protein digestibility is first limiting, the amino acid score for a protein mixture should be calculated from the weighted average digestible amino acid content. This is in contrast to the FAO/WHO 1991 report $^{(4)}$.

\section{Conclusions of the WHO/FAO/UNU 2002 Expert Consultation regarding protein quality assessment}

It was concluded that a complete listing of the digestibility and amino acid scores of food proteins based on updated data on amino acid composition, and on the new scoring pattern quoted in the FAO/WHO/UNU 2007 report $^{(5)}$ would be the subject of a new technical report. Meanwhile, the principles discussed in the 2007 report can be applied. Therefore, protein quality assessed in terms of a PDCAAS value is calculated from the best estimate of protein digestibility and the amino acid score based on a comparison of the amino acid composition of digestible protein with the scoring pattern appropriate for age, It is evident that when such PDCAAS values are used to adjust the intakes of the dietary mixture to meet the safe level, the score of the mixture should not be $>1$ or 100. However, the case for giving non-truncated amino acid scores $>1$ or 100 for individual protein sources will require further evaluation. 
Since the FAO/WHO 1991 report $^{(4)}$, significant advances have been made in methods for the amino acid analysis of foods and for determining amino acid digestibility. Moreover, the $\mathrm{FAO}^{(67)}$ technical report recommends that protein should be measured as the sum of individual amino acid residues (the molecular weight of each amino acid less the molecular weight of water) plus free amino acids. Since there is no official AOAC (Association of Official Analytical Communities) International method for amino acid analysis of foods, collaborative research and scientific consensus would be required to achieve this objective.

\section{Overall conclusions}

Total protein in a food should be accurately measured as the sum of amino acid residues (sum of molecular weight of each amino acid less the molecular weight of $\mathrm{H}_{2} \mathrm{O}$ ). This method would obviate the need of using nitrogen to protein conversion factors.

Three hydrolyses, including acid hydrolysis of unoxidized protein for the determination of all amino acids except tryptophan, methionine and cystine; acid hydrolysis of oxidized protein for the determination of methionine and cystine; and alkaline hydrolysis of unoxidised protein for tryptophan have been standardized. The separation and quantitation of the released amino acids by IEC (ion-exchange chromatography) using cation exchange resins and postcolumn derivatization by a commercial amino acid analyzer have also been standardized. The standardized amino acid analysis methods can provide data with between laboratories reproducibility of about $10 \%$ for most amino acids. More recently, the HPLC method after precolumn derivatization with PITC (phenylisothiocyanate) has been extensively used for the determination of all amino acids in hydrolysates of a variety of foods and faeces with speed and accuracy. The HPLC results agree with those obtained by conventional IEC. There is, however, a need to standardize and measure the accuracy and precision of the PITC derivatization method for the quantitative determination of amino acids in protein hydrolysates in an interlaboratory study. Further collaborative research is required to develop an official AOAC International method for amino acid determination in foods and faeces/digesta.

There is strong evidence that faecal digestibility values do not accurately differentiate between dietary proteins due to the effects of microbial metabolism in the large intestine. Therefore, it is recommended that digesta collected at the end of the small intestine (the terminal ileum), be used for the determination of digestibility values. This will increase the accuracy and sensitivity of the assay. The pig may be a better animal model than the rat because the pig is a mealeating species and does not practice coprophagy as does the rat. Moreover, the gastrointestinal anatomy, physiology and metabolism of pigs are very similar to those of humans. A comparison of the true ileal digestibility of amino acids by the pig and human shows little difference which strongly supports the validity of using the pig as a model for the human in protein digestibility studies. However, standardization of the pig true ileal digestibility assay and sufficient data on amino acid digestibility in foods are required before the replacement of the rat faecal method by the pig ileal method can be implemented.

There are two distinct applications of the protein quality assessment methods including one for meeting human amino acid needs and the second for regulatory purposes to ensure protein adequacy of foods and food products sold to consumers.

The PDCAAS (protein digestibility-corrected amino acid score) method, as adopted by FAO/WHO (1991) remains the preferred method for routine prediction of protein quality of properly processed (containing minimal amounts of residual antinutritional factors) and highly digestible (where digestibility of protein is a good approximation of bioavailability of individual amino acids) food products for human nutrition. The following analytical revisions have been suggested to improve the accuracy and wider applicability of the PDCAAS method.

In evaluating protein quality of a food product, protein digestibility is the first limiting factor. Therefore, amino acid score should be calculated from the contents of digestible amino acids (i.e. the correction for protein digestibility should be applied before and not after calculating amino acid score).

Amino acid score for a dietary mixture, where the protein digestibility of individual components varies, should be calculated from the weighted average digestible amino acid content.

For regulatory purposes, the PDCAAS method (unlike biological assays such as PER) fails to recognize the additional value of high quality animal proteins. Therefore, there is a need to revise the calculation of PDCAAS to permit values $>1$ or 100 for high quality proteins, especially if they are intended to be used as supplements to other low quality proteins. However, this revision would not be needed in calculating PDCAAS for protein mixtures, where the supplemental excess of amino acids is included in the calculation. Moreover, this revision would be of no practical utility in the case of sole source foods.

Literature reports using standardized methodology and corrected for true ileal amino acid digestibility would support the use of the FAO/WHO (1991) scoring pattern for assessing protein quality in foods for infants less than one year of age. It would also suggest the need to include a desirable cysteine/ methionine ratio (of about 2.0) in the scoring pattern.

At the present, PDCAAS values are corrected for the digestibility of protein as opposed to individual amino acids in a protein. However, there are often quite large differences between digestibility values for proteins and the individual amino acids. The accuracy of PDCAAS would be improved by determining individual amino acid digestibility values as opposed to only that for protein. It should also be noted that when a dietary protein has undergone some form of heat treatment or has been stored for a prolonged period of time, the availability of some amino acids, particularly lysine, might be underestimated using the conventional true ileal digestibility assay. The assay must be modified to account for the damage to heat sensitive amino acids. In such cases, 
other methods such as the true ileal reactive lysine digestibility assay are required to give accurate results.

The PDCAAS may not be appropriate for routine assessment of protein quality of sole source foods such as infant formulas and enteral nutritionals, protein sources containing high levels of known antinutritional factors (both present naturally or formed during processing or prolonged storage), protein products co-limiting in more than one IAA, and amino acid supplemented-poor quality proteins. The protein quality of such products should be evaluated by a biological assay such as a rat assay.

The RNPR (relative net protein ratio) method is the best rat assay for routine assessment of protein quality of foods. The RNU (relative nitrogen utilization) method gives essentially the same values as RNPR. Unlike the RNPR method where protein needed for maintenance is measured by feeding a non-protein diet, in the RNU method the factor for maintenance is calculated based on the initial and final weights of rats. The elimination of the need for feeding of a "zero" protein diet to a group of rats in the RNU method makes it less costly compared to the RNPR method. It is, therefore, recommended that the RNU method should be used for routine protein quality assessment of those foods where the use of the PDCAAS method is not appropriate.

\section{Acknowledgements}

(a) Gilani, G. S. As the sole author contributed entirely to the reserach.

(b) The author states that there are no conflicts of interest.

(c) The research received no specific grant from any funding agency in the public, commercial or not-for-profit sectors.

The assistance of Patrick Robertson in the preparation of this manuscript is highly appreciated.

\section{References}

1. Harper AE (1981) Task force II report. In Protein Quality in Humans: Assessment and In Vitro Estimation, pp. 417-420 [CE Bodwell, JS Adkins and DT Hopkins, editors]. AVI Publishing Inc: Westport, Connecticut.

2. Bodwell CE, Adkins JS \& Hopkins DT (1981) Protein Quality in Humans: Assessment and In Vitro Estimation. Westport, Connecticut: AVI Publishing Company Inc.

3. Codex Alimentarius Commission (1989) Document Alinorm 89/30, Working Group's Report of the Fifth Session of CCVP on Protein Quality Measurement. Geneva, Rome: FAO, WHO.

4. FAO/WHO (1991) Protein Quality Evaluation: Report of the Joint FAO/WHO Expert Consultation, FAO Food and Nutrition Paper 51. Rome: FAO.

5. FAO/WHO (2001) Report of the FAO/WHO Working Group on Analytical Issues Related to Food Composition and Protein Quality. Rome: FAO.

6. WHO/FAO/UNU (2007) Protein and Amino Acid Requirements in Human Nutrition; Report of a joint WHO/FAO/ UNU Expert Consultation, WHO Tech Rep Ser no. 935. Geneva: WHO.

7. Reeds P, Schaafsma G, Tome D, et al. (2000) Summary of recommendations. J Nutr 130, 1874S-1876S.
8. AOAC (2000). Official Methods of Analysis of the Association of Official Analytical Chemists International 17th edition, section 45.3.04 (AOAC Official Method 960·48, Protein Efficiency Ratio), section 45.3.05 (AOAC Official Method 982.30, protein Efficiency Ratio, Calculation Method) section 45.3.06 (AOAC Official Method 991.29; True Protein Digestibility of Foods and Food Ingredients, Rat Bioassay), section 45.4.04 (AOAC Official Method 988.15, Tryptophan in Foods and Food and Feed Ingredients), section 45.4.05 (AOAC Official Method 985.28, Sulfur Amino Acids in Food and Feed Ingredients, Ion-Exchange Chromatographic method: Extension to Processed Foods), Association of Official Analytical Chemists International, Gaithersburg, Maryland.

9. McLaughlan JM (1974) Evaluation of standard rat assays. In Nutrients in processed Foods-Proteins, pp. 69-76 [PH White and DC Fletcher, editors]. Acton, MA: Publishing Sciences Group Inc.

10. Campbell JA \& Chapman DG (1959) Evaluation of protein in foods: Criteria for describing protein value. J Can Dietet Assoc 21, 51-58.

11. Samonds KW \& Hegsted DM (1977) Animal bioassays: a critical evaluation with specific reference to assessing nutritive value for the human. In Evaluation of Proteins for Humans, pp. 68-80 [CE Bodwell, editor]. Newport, CT: AVI Publishing Co Inc.

12. UNU (1980) Some rat and human bioassay procedures. In Nutritional Evaluation of Food Proteins, pp. 103-117 [PL Pellet and VR Young, editors]. Tokyo, Japan: The United Nations University.

13. Bender AE \& Doell BH (1957) Biological evaluation of proteins: a new aspect. Br J Nutr 11, 140.

14. Hackler LR, Bodwell CE, Happich ML, et al. (1984) Protein efficiency ratio: AACC/ASTM collaborative study. I Assoc Off Anal Chem 67, 66-77.

15. Sarwar G, Blair R, Friedman M, et al. (1984) Inter- and intralaboratory variability in rat growth assays for estimating protein quality of foods. J Assoc Off Anal Chem 67, 976-981.

16. Happich ML, Bodwell CE, Hackler LR, et al. (1984) Net protein ratio data. AACC-ASTM collaborative study. $J$ Assoc Off Anal Chem 67, 255-262.

17. Sarwar G \& McLaughlan JM (1981) Relative net protein ratio method for evaluating protein quality. Nutr Rep Intern $\mathbf{2 3}$, $1157-1166$.

18. Henry KM (1965) A comparison of biological methods with rats for determining the nutritive value of proteins. Br J Nutr 19, 125-135.

19. McLaughlan JM (1976) The relative nitrogen utilization method for evaluating protein quality. J Assoc Off Anal Chem 59, 42-45.

20. McLaughlan JM, Anderson GH, Hackler LR, et al. (1980) Assessment of rat growth methods for estimating protein quality: interlaboratory study. J Assoc Off Anal Chem 63, $462-467$.

21. Steinke FH (1979) Measuring protein quality of foods. In Soy Protein and Human Nutrition, pp. 307-312 [HL Wilcke, DT Hopkins and DH Waggle, editors]. New York, NY: Academic Press.

22. Sarwar G, Peace RW \& Botting HG (1985) Corrected relative net protein ratio (CRNPR) method based on differences in rat and human requirements for sulfur amino acids. $J$ Assoc Off Anal Chem 68, 689-693.

23. Young VR, Wayler A, Oarza C, et al. (1984) A long-term metabolic study in young men to assess the nutritional quality of an isolated soy protein and beef protein. Am J Clin Nutr 39, 8-15. 
24. FAO/WHO-United Nations University (1985) Energy and Protein Requirements: Report of a Joint FAO/WHO/UNU Expert Consultation, WHO Tech Rep Ser no.724. Geneva: WHO.

25. Bodwell CE, Carpenter KJ \& McDonough FE (1989) A collaborative study of methods of protein evaluation: Introductory paper. Plant Foods Hum Nutr 39, 3-11.

26. McDonough FE, Sarwar G, Steinke FH, et al. (1990) A collaborative study of methods of protein evaluation: In vitro assay for protein digestibility: interlaboratory study. $J$ Assoc Off Anal Chem 73, 622-625.

27. McDonough FE, Steinke FH, Sarwar G, et al. (1990) In vivo assay for true digestibility: collaborative study. I Assoc Off Anal Chem 73, 801-805.

28. Eggum BO (1973) A study of certain factors influencing protein utilization in rats and pigs. Publication 406. Copenhagen: National Institute of Animal Science.

29. Saterlee LD, Marshall HF \& Tennyson JM (1979) Measuring protein quality. J Am Oil Chem Soc 56, 103-109.

30. Pederson B \& Eggum BO (1983) Prediction of protein digestibility by an in vitro enzymatic $\mathrm{pH}$ stat procedure. ZfTierphysiol Tierernahrg u Futtermittelkde 49, 265-277.

31. European Commission (1996) Commission Directive 96/4/EC, Euratom of 16 February amending Directive 911321/EEC on infant formulae and follow-on formulae (Text with EEA relevance). Off J Eur Communities No. L049, 12-16.

32. Atkinson SA \& Lonnerdal B (1989) Protein and Non-protein Nitrogen in Human Milk. Boca Raton: CRC Press Inc.

33. Darragh AJ \& Moughan PJ (1988) The amino acid composition of human milk corrected for amino acid digestibility. Br J Nutr 80, 25-34.

34. Davis TA, Nguyen HV, Garcia-Bravo R, et al. (1994) Amino acid composition of human milk is not unique. J Nutr 124, $1126-1132$

35. Janas LM, Picciano MF \& Hatch TF (1987) Indices of protein metabolism in term infants fed either human milk or formulas with reduced protein concentration and various whey/casein diets. J Pediatrics 110, 838-848.

36. Nayman R, Thomson ME, Scriver CR, et al. (1979) Observations on the composition of milk-substitute products for the treatment of inborn errors of amino acid metabolism. Comparisons with human milk. A proposal to rationalize nutrient content of treatment products. Am J Clin Nutr 32, 1279-1289.

37. Rigo J, Salle BL, Cavero E, et al. (1994) Plasma amino acid and protein concentrations in infants fed human milk or a whey protein hydrolysate formula during the first month of life. Acta Paediatrica 83, 127-131.

38. Sarwar G, Darling P, Ujiie M, et al. (1996) Use of amino acid profiles of preterm and term human milks in evaluating scoring patterns for routine protein quality assessment of infant formulas. JAOAC International 79, 498-502.

39. Svanberg D, Gebre-Medhin M, Ljungqvist B, et al. (1977) Breast milk composition in Ethiopian and Swedish mothers. III. Amino acids and other nitrogenous substances. Am J Clin Nutr 30, 499-507.

40. United Kingdom Department of Health and Social Security (1977) The composition of mature human milk. Report of a working party of the committee on medical aspects of food policy. Report on Health and Social Subjects No. 12. London: Her Majesty's Stationery Office.

41. Villalpando S, Butte NF, Flores-Huerta S, et al. (1998) Qualitative analysis of human milk produced by women consuming a maize-predominant diet typical of rural Mexico. Ann Nutr Met 42, 23-32.
42. Life Sciences Research Office (1998) Assessment of Nutrient Requirements for Infant Formulas. LSRO, Bethesda, Maryland: American Society for Nutritional Sciences.

43. Hambraeus L, Fransson G-B \& Lonnerdal B (1984) Nutritional availability of breast milk protein. Lancet 2, 167-168.

44. van Woelderen BF (1987) Changing insights into human milk proteins; some implications. Nutr Abs Rev (Series A) 57, 129-134.

45. McNeil NI (1988) Nutritional implication of human mammalian large intestine function. Wld Rev Nutr Dietet 56, 1-42.

46. Sarwar G (1997) The protein digestibility-corrected amino acid score method overestimates quality of proteins containing antinutritional factors and of poorly digestible proteins supplemented with limiting amino acids in rats. $J$ Nutr 127, 758-764.

47. Fenwick RM, Knighton DR \& Moughan PJ (1995) Protein quality measurement by the PDCAAS technique. International dairy Fed Nutr Newsletter 4, 40-43.

48. Mitchell GV, Jenkins MY \& Grundel E (1989) Protein efficiency ratios and net protein ratios of selected protein foods. Plant Foods Hum Nutr 39, 53-58.

49. Tome D \& Bos C (2000) Dietary protein and nitrogen utilization. J Nutr 130, 1868S-1873S.

50. Rackis JJ \& Gumbmann MR (1981) Protease inhibitors: Physiological properties and nutritional significance. In Antinutrients and Natural Toxicants in Food, pp. 203-207 [RL Ory, editor]. Westport, Connecticut: Food and Nutrition Press Inc.

51. Friedman M, Gumbmann MR \& Masters PM (1984) Proteinalkali reactions: chemistry, toxicology, and nutritional consequences. In Nutritional and Toxicological Aspects of Food Safety, pp. 367-412 [M Friedman, editor]. New York, NY: Plenum Press.

52. Hurrell RF (1984) Reactions of food proteins during processing and storage and their nutritional consequences. In Developments in Food Proteins, pp. 213-244 [BJF Hudson, editor]. Vol. 3, London, England: Applied Science Publishers.

53. Sarwar G, L' Abbe MR, Trick J, et al. (1999) Influence of feeding alkaline/heat processed proteins on growth and protein and mineral status of rats. Adv Exp Med Biol 459, $161-177$

54. Sarwar G \& Peace RW (1986) Comparisons between true digestibility of total nitrogen and limiting amino acids in vegetable proteins. J Nutr 116, 1172-1184.

55. Food Chemical News (1991) March 18EC dairy group questions proposed protein labelling, Vol. 33, pp. 42. Washington, DC: CRC Press Inc.

56. Sarwar G, Peace RW \& Botting HG (1993) Effect of amino acid supplementation on protein quality of soy-based infant formulas fed to rats. Plant Foods Hum Nutr 43, 259-266.

57. FAO/WHO (1973) Energy and Protein Requirements; report of a joint FAOIWHO ad hoc expert committee, WHO Tech Rep Ser no. 522. Geneva: WHO.

58. USDA (1963) Composition of Foods: Handbook 8. Washington, DC: United Sates Department of Agriculture.

59. AOAC (1984) Official Methods of Analysis of the Association of Official Analytical Chemists, 14th edition Arlington, VA: Association of Official Analytical Chemists.

60. Tkachuk R (1969) Nitrogen-to-protein conversion factors for cereals and oilseed meals. Cereal Chem 30, 1190-1206.

61. Sosulski FW \& Imafidon GI (1990) Amino acid composition and nitrogen-to-protein conversion factors for animal and plant Foods. J Agri Food Chem 38, 1351-1356.

62. Batterham ES, Anderson LM, Baigent RD, et al. (1990) A comparison of the availability and ileal digestibility of 
lysine in cottonseed and soybean meals for grower/finisher pigs. Br J Nutr 64, 663-667.

63. Moughan PJ \& Rutherfurd SM (1996) A new method for determining digestible reactive lysine in foods. J Agri Food Chem 44, 2202-2209.

64. Hegsted DM (1963) Variation in requirements of nutrients: amino acids. Fed Proc 22, 1424-1430.
65. Moughan PJ (2003) Amino acid availability aspects of chemical analysis and bioassay methodology. Nutr Res Rev 16, 127-141.

66. Darragh AJ \& Hodgkinson SM (2000) Quantifying the digestibility of dietary protein. J Nutr 130, 1850S-1856S.

67. FAO (2003) Food energy-methods of analysis and conversion factors. FAO Food and Nutrition Paper no. 7. Rome: FAO. 